\title{
Syntheses of (4,1-Benzoxazepine-3-ylidene)acetic Acid Derivatives and Their Inhibition of Squalene Synthase ${ }^{1)}$
}

\author{
Takashi Miki,* Masakuni Kori, Ryu-ichi Tozawa, Masahira Nakamura, Yasuo SugiYama, and \\ Hidefumi YUKIMASA \\ Takeda Chemical Industries, Ltd., Pharmaceutical Research Division, 2-17-85 Juso-Honmachi, Yodogawa-ku, Osaka \\ 532-8686, Japan. Received July 30, 2001; accepted October 1, 2001
}

\begin{abstract}
The (3,5-trans)-7-chloro-5-(2-chlorophenyl)-2-oxo-1,2,3,5-tetrahydro-4,1-benzoxazepine-3-acetic acid derivatives 1 have been previously identified as potent squalene synthase inhibitors. A series of (4,1-benzoxazepin-3-ylidene)acetic acid derivatives were synthesized and evaluated for their inhibition of rat and human squalene synthase, and the $(E)$-isomers were found to exhibit potent inhibitory activity, with the same potency as 4,1-benzoxazepine-3-acetic acid derivatives. In contrast the $(Z)$-isomers did not exhibit significant inhibitory activity, and the active conformation of the 4,1-benzoxazepine-3-acetic acid derivatives was deduced from the folded conformation of the $(E)$-isomers.
\end{abstract}

Key words squalene synthase; 4,1-benzoxazepine-3-acetic acid; active conformation; conformationally restricted analogue; (4,1-benzoxazepin-3-ylidene)acetic acid derivative; hypocholestemic agent

Squalene synthase [EC 2.5.1.21] catalyzes the dimerization of farnesyl diphosphate to squalene in cholesterol biosynthesis. This enzymatic step occurs after the pathway branches to other non-steroidal isoprenoids such as dolicol, ubiquinones and isopentenyl t-RNA. Since squalene synthase inhibitors do not interfere with the biosynthesis of these isoprene derivatives, inhibition of this step would arrest only cholesterol biosynthesis and might be useful for the treatment of hyperlipidemia.

In previous papers, ${ }^{1)}$ we have described chemical modification of (3,5-trans)-7-chloro-5-phenyl-2-oxo-1,2,3,5-tetrahydro-4,1-benzoxazepine-3-acetic acid derivatives and evaluation of their inhibition of squalene synthase. Through the structure-activity relationship study, compounds $\mathbf{1 a}-\mathbf{c}$, which have an alkyl group at the 1-position, were found to be potent inhibitors (Fig. 1). In these compounds the conformations of fused ring systems are rigid, but that of the carboxymethyl group at the 3-position, which was essential for potent activity, is very flexible. Thus we considered that restriction of the flexibility of the 3-acetic acid moiety would yield useful information concerning the active conformation of these compounds. We report here the preparation of the (4,1-benzoxazepin-3-ylidene)acetic acid derivatives in which a double bond was introduced between the 3-position and $\alpha$ position (Fig. 1, 2-4) and the evaluation of their inhibition of squalene synthase. ${ }^{2)}$
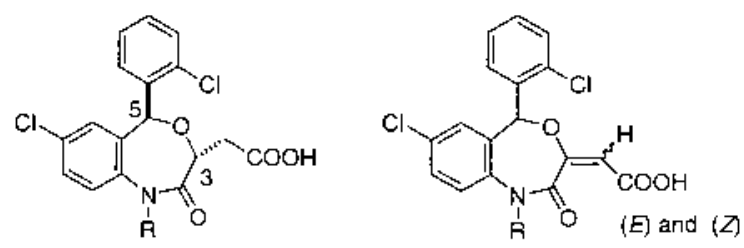

$$
\begin{aligned}
& \text { 1a: } \mathrm{A}=\mathrm{Pr}^{i} \\
& \text { 1b: } \mathrm{R}=\mathrm{Pr}^{\mathrm{n}} \\
& \text { 1c: } \mathrm{A}=\mathrm{Bu} \mathrm{u}^{i}
\end{aligned}
$$$$
\text { 2: } \dot{F}=P r^{j}
$$$$
\text { a } P=P r^{n}
$$$$
\text { 4: } R=B u^{4}
$$

\section{Chemistry}

The epoxy-amide derivative $\mathbf{6 a}$ was prepared by acylation of the racemic 2-aminobenzylalcohol derivative $\mathbf{5 a}^{1 b)}$ with the acid chloride prepared from DL-trans-epoxysuccinic acid monoethyl ester ${ }^{3)}$ and dichloromethylenedimethyliminium chloride. ${ }^{4)}$ Intramolucular cyclization ${ }^{5)}$ of the epoxy-amide derivative 6a afforded a $c a$. $1: 1$ mixture of two products, which were separated by fractional recrystallization to yield the compounds $\mathbf{7 a}$ and $\mathbf{7 b}$ (Chart 1). ${ }^{6}$ The structures of $\mathbf{7 a}$ and $7 \mathbf{b}$ were determined by X-ray diffraction analysis, and are shown in Figs. 2 and 3. Both of these compounds are 7membered 4,1-benzoxazepine derivatives and the configurations of $7 \mathbf{a}$ and $7 \mathbf{b}$ were determined to be $(3 R S, 5 S R, \alpha S R)$ and $(3 R S, 5 R S, \alpha S R)$, respectively. The fact that $7 \mathbf{a}$ and $7 \mathbf{b}$ have the same configurations at the 3 - and $\alpha$-positions indicate intramolecular cyclization of $\mathbf{6 a}$ proceeded by attack of the oxygen anion on the epoxy carbon bound to the carbamoyl group from the opposite face of the epoxy oxygen (Fig. 4).<smiles>CCOC(=O)[C@@H]1O[C@H]1C(=O)N(c1ccc(Cl)cc1C(O)c1ccccc1Cl)C(C)C</smiles>

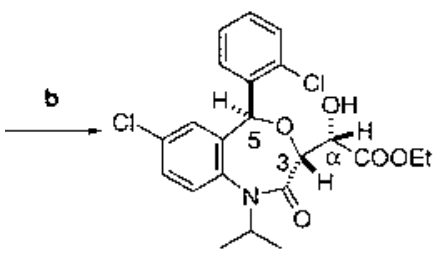

$(3 R S, 5, S A, \alpha S A)$

7 a

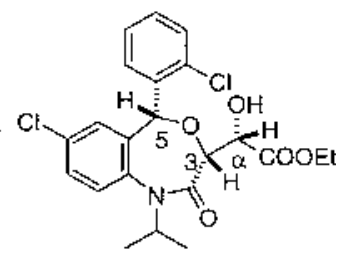

(3RS,5RS, OSA)

$7 \mathrm{~b}$
Reagents: (a) DL-trans-Epoxysuccinic acid monoethyl ester, dichloromethylenedimethyliminium chloride, $\mathrm{NaHCO}_{3}, \mathrm{CH}_{2} \mathrm{Cl}_{2}$; (b) 1) $\mathrm{K}_{2} \mathrm{CO}_{3}$, EtOH, 2) fractional recrystallization.

Fig. 1. Structures of 4,1-Benzoxazepine Derivatives 

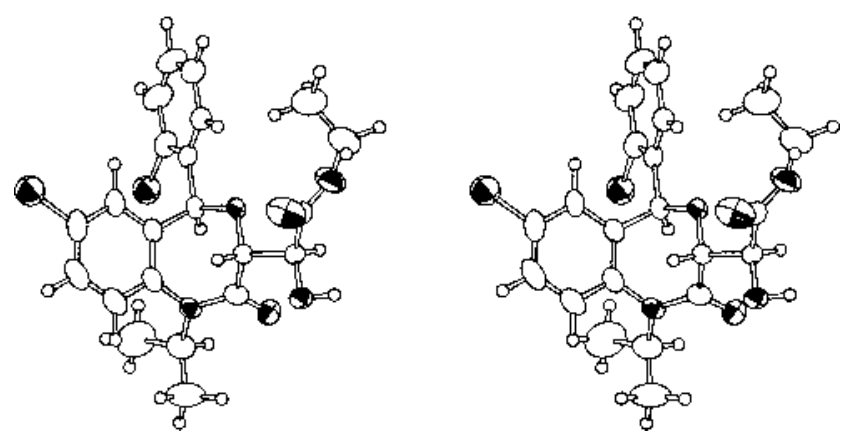

Fig. 2. Stereoscopic Molecular View of Compound 7a
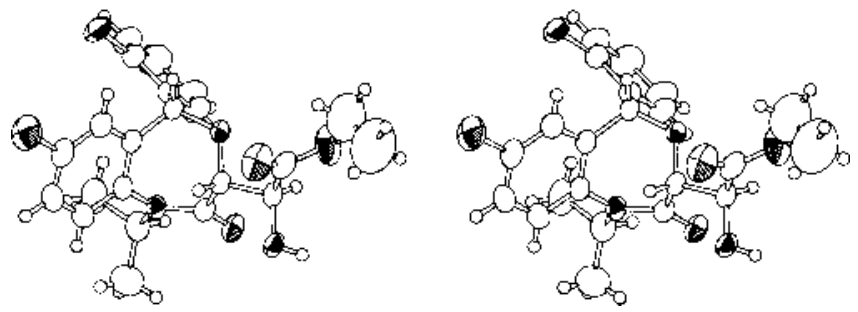

Fig. 3. Stereoscopic Molecular View of Compound 7b

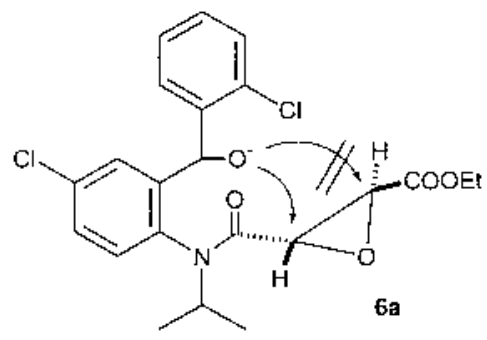

Fig. 4. Mechanism of Cyclization of $\mathbf{6 a}$

Compound 7a was methanesulfonylated, and the resulting mesylate 8a was treated with cesium propionate ${ }^{7)}$ to yield a mixture of two products (Chart 2). Elimination of the mesyloxy group with sodium acetate instead of cesium propionate proceeded slowly and required excess amount of sodium acetate. Separation of the mixture by column chromatography gave 9a (more polar isomer) and 9b (less polar isomer) in $1: 2$ ratio. Elemental analysis of these compounds indicated that they have the same composition and mass spectra of both compounds showed a molecular ion peak at $\mathrm{m} / \mathrm{z} 433$ $\left(\mathrm{M}^{+}\right)$. Their IR spectra exhibited very similar patterns and in the ${ }^{1} \mathrm{H}$-NMR spectra singlet signals due to olefin protons were observed at $\delta 5.41$ and $5.48 \mathrm{ppm}$ of $9 \mathbf{a}$ and $9 \mathbf{b}$, respectively. On the basis of these results, $9 \mathbf{a}$ and $9 \mathbf{b}$ were determined to be geometrical isomers of (4,1-benzoxazepin-3-ylidene)acetic acid derivatives. Compounds $9 \mathbf{a}$ and $\mathbf{9 b}$ were then hydrolyzed to the acids $\mathbf{2 a}$ and $\mathbf{2 b}$, respectively and configuration of the double bond was established by X-ray diffraction analysis of compound 2a. As shown in Fig. 5, compound $2 \mathbf{a}(\mathbf{9 a})$ was determined to be the $(E)$-isomer, and thus by inference, compound $\mathbf{2 b}(\mathbf{9 b})$ was the $(Z)$-isomer.

Compound $\mathbf{7 b}$, which is a diastereoisomer of $\mathbf{7 a}$, could also be converted to $\mathbf{9 a}, \mathbf{b}$ by mesylation, and subsequent treatment of the resulting $\mathbf{8 b}$ with cesium propionate. The ratio of $9 \mathbf{a}$ and $9 \mathbf{b}(1: 2)$ prepared from $7 \mathbf{b}$ was identical to that obtained from $7 \mathbf{a}(\text { Chart } 3)^{8}{ }^{8}$

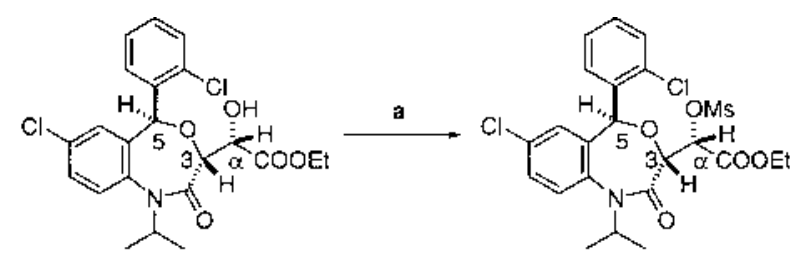

(3AS, 5SR, वSF)

(3PS, 5SR, aSP

$7 a$

8a<smiles>CCOC=C1OC(c2ccccc2Cl)c2cc(Cl)ccc2N(C(=O)C=CC(=O)OCC)C1=O</smiles><smiles>CC(C)N1C(=O)C(C(C(=O)O)C(F)F)OC(c2ccccc2Cl)c2cc(Cl)ccc21</smiles>

$2 a$

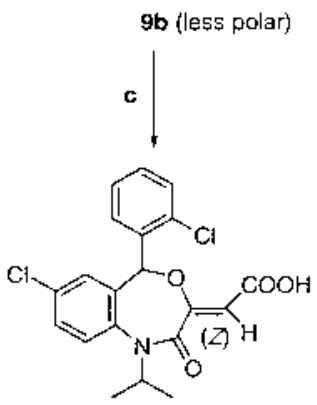

$2 b$

Reagents: (a) $\mathrm{MsCl}, \mathrm{Et}_{3} \mathrm{~N}$, AcOEt; (b) 1) $\mathrm{CH}_{3} \mathrm{CH}_{2} \mathrm{COOCs}$, DMF, 2) chromatographic separation; (c) $1 \mathrm{~N} \mathrm{NaOH}$, EtOH.

Chart 2
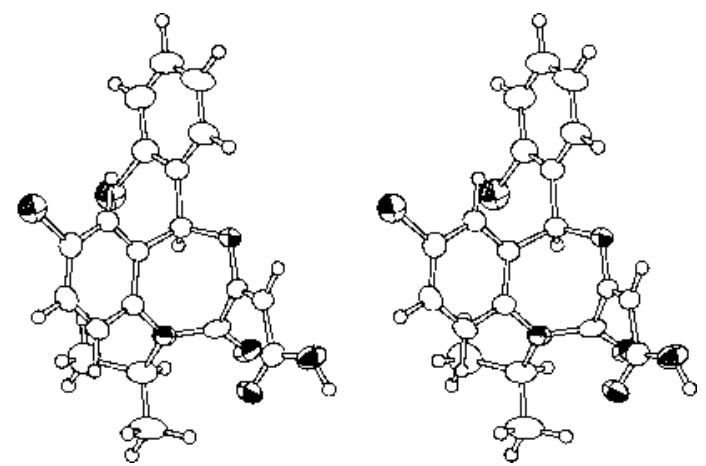

Fig. 5. Stereoscopic Molecular View of Compound 2a

The syntheses of the (4,1-benzoxazepin-3-ylidene)acetic acid derivatives $\mathbf{3}$ and $\mathbf{4}$, which have an $n$-propyl and isobutyl group at the 1-position, are outlined in Chart 4. Acylation of racemic aminobenzylalcohol derivatives $\mathbf{5} \mathbf{b}^{1 b)}$ and $\mathbf{5} \mathbf{c}^{1 b)}$ with the acid chloride obtained from DL-trans-epoxysuccinic acid monoethyl ester afforded the epoxy-amide $\mathbf{6 b}, \mathbf{c}$. Intramolecular cyclization of $\mathbf{6 b}, \mathbf{c}$ gave a diastereomeric mixture of $\alpha$ hydroxyacetic acid derivatives 10a, $\mathbf{b}$ which were mesylated to give 11a and 11b. Subsequent treatment with cesium propionate, followed by chromatographic separation afforded 12a, $\mathbf{b}$ and 13a, $\mathbf{b}$, respectively. The configurations of 12a, $\mathbf{b}$ and 13a, $\mathbf{b}$ were determined by comparison of the chemical shifts of signals due to olefin protons in the ${ }^{1} \mathrm{H}-\mathrm{NMR}$ spectra of 9,12 and 13. Alkaline hydrolysis of 12a, b and 13a, b yielded the carboxylic acid derivatives $3 \mathbf{a}, \mathbf{b}$ and $4 \mathbf{a}, \mathbf{b}$, re- 


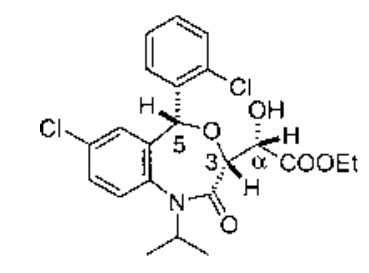

(3RS, 5RS, $\alpha S R)$

$7 b$

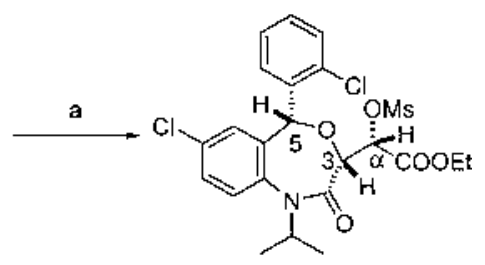

(3AS, 5AS, OSA)

$8 b$

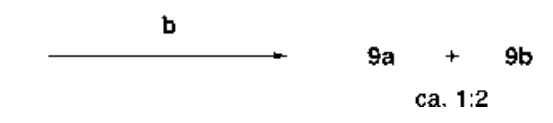

Reagents: (a) $\mathrm{MsCl}, \mathrm{Et}_{3} \mathrm{~N}$, AcOEt; (b) 1) $\mathrm{CH}_{3} \mathrm{CH}_{2} \mathrm{COOCs}$, DMF, 2) chromatographic separation.

Chart 3

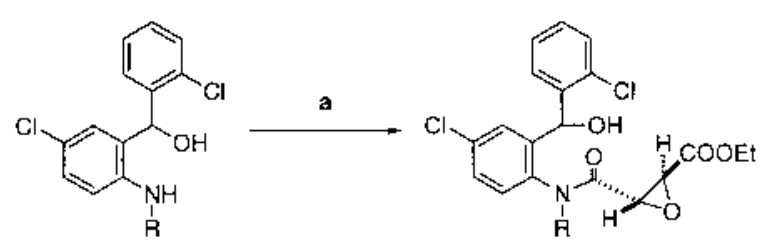

(t) $-5 \mathbf{b}: R=\mathrm{Pr}^{\mathrm{n}}$

$\left( \pm f-5 c: R=B u^{i}\right.$<smiles>CCOC(=O)C(O)C1OC(c2ccccc2Cl)c2cc(Cl)ccc2NC1=O</smiles>

Gb: $R=P r^{n}$

Ge: $: R=B u^{\prime}$

$10 a: A=P r^{n}$

$10 \mathrm{~b}: \mathrm{A}=\mathrm{Bu} \mathrm{U}^{\mathrm{E}}$<smiles>CCOC(C)(C)[C@H]1O[C@H](c2ccccc2Cl)c2cc(Cl)ccc2NC1=O</smiles>

A $O$

11b : $\mathrm{A}=\mathrm{Eu}^{\mathrm{i}}$

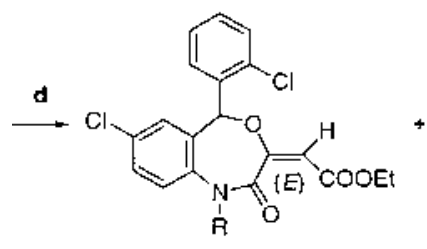

12a : $\mathrm{A}=\operatorname{Pr}^{\mathrm{n}}$ (more polar)

$13 a: A=B u^{i}($ more polar)

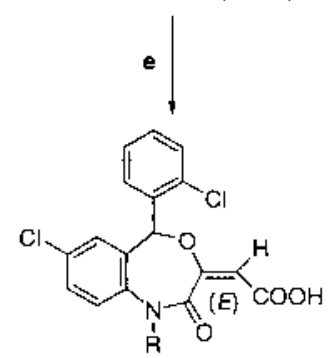

$3 a: R=P r^{n}$

$4 a: R=B u^{\prime}$ 12b: $R=\operatorname{Pr}^{n}$ (less polar $\}$ $13 b: A=B u^{i}$ (less polar)

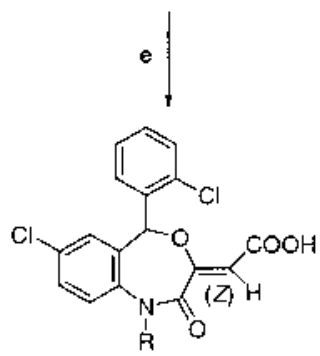

$B: A=P r^{n}$

4b: $R=B u^{\prime}$
Reagents: (a) DL-trans-Epoxysuccinic acid monoethyl ester, dichloromethylenedimethyliminium chloride, $\mathrm{NaHCO}_{3}, \mathrm{CH}_{2} \mathrm{Cl}_{2}$; (b) $\mathrm{K}_{2} \mathrm{CO}_{3}$, EtOH; (c) $\mathrm{MsCl}, \mathrm{Et}_{3} \mathrm{~N}$, AcOEt; (d) 1) $\mathrm{CH}_{3} \mathrm{CH}_{2} \mathrm{COOCs}, \mathrm{DMF}$, 2) chromatographic separation; (e) $1 \mathrm{~N} \mathrm{NaOH}, \mathrm{EtOH}$.

\section{Chart 4}

spectively.

\section{Biological Results and Discussion}

The compounds synthesized were evaluated for inhibition
Table 1. Squalene Synthase Inhibitory Activities of ( \pm )-[7-Chloro-5-(2chlorophenyl)-2-oxo-1,5-dihydro-4,1-benzoxazepin-3-ylidene]acetic Acid Derivatives (2-4) and ( \pm )-(3,5-trans)-7-Chloro-5-(2-chlorophenyl)-2-oxo1,2,3,5-tetrahydro-4,1-benzoxazepine-3-acetic Acid Derivatives (1)<smiles>O=C(O)/C=C1/OC(c2ccccc2Cl)c2cc(Cl)ccc2NC1=O</smiles><smiles>O=C(O)C[C@H]1OC(c2ccccc2Cl)c2cc(Cl)ccc2N1P</smiles>

1

\begin{tabular}{|c|c|c|c|c|}
\hline \multirow{2}{*}{ Compd. } & \multirow{2}{*}{ Config. } & \multirow{2}{*}{$\mathrm{R}$} & \multicolumn{2}{|c|}{$\mathrm{IC}_{50}(\mu \mathrm{M})^{a)}$} \\
\hline & & & Rat enzyme & Human enzyme \\
\hline $2 \mathbf{a}$ & $E$ & $\operatorname{Pr}^{\mathrm{i}}$ & 0.31 & 0.17 \\
\hline $2 b$ & $Z$ & $\operatorname{Pr}^{\mathrm{i}}$ & $>10(21.6)^{b)}$ & c) \\
\hline $3 \mathbf{a}$ & $E$ & $\operatorname{Pr}^{\mathrm{n}}$ & 0.076 & 0.098 \\
\hline $3 \mathbf{b}$ & $Z$ & $\operatorname{Pr}^{\mathrm{n}}$ & 8.4 & -c) $^{c}$ \\
\hline $4 a$ & $E$ & $\mathrm{Bu}^{\mathrm{i}}$ & 0.11 & 0.041 \\
\hline $4 \mathrm{~b}$ & $Z$ & $\mathrm{Bu}^{\mathrm{i}}$ & $>10(14.5)^{b)}$ & $ـ^{c)}$ \\
\hline $\mathbf{1 a}^{d)}$ & & $\operatorname{Pr}^{\mathrm{i}}$ & 0.71 & 0.54 \\
\hline $\mathbf{1 b}^{d)}$ & & $\operatorname{Pr}^{\mathrm{n}}$ & 0.14 & -c) $^{c}$ \\
\hline $1 \mathbf{c}^{(d)}$ & & $\mathrm{Bu}^{\mathrm{i}}$ & 0.061 & 0.034 \\
\hline
\end{tabular}

a) $\mathrm{IC}_{50}$ values were determined by a single experiment run in duplicate. b) \% Inhibition at $10^{-5} \mathrm{M}$. c) Not tested. d) Reference $1 b$.

of squalene synthase prepared from rat liver and human hepatoma (HepG2) cells. Inhibitory activities were measured according to the method of Cohen et al. with slight modification. ${ }^{9)}$

Inhibitory activities of the (4,1-benzoxazepin-3-ylidene)acetic acid derivatives $\mathbf{2}-\mathbf{4}$ for squalene synthase are shown in Table 1 . It can be seen that the inhibitory activity of the (E)-isomers $\mathbf{2 a}, \mathbf{3 a}$ and $\mathbf{4 a}$ are of similar potency as the corresponding acetic acid derivatives $1 \mathbf{a}-\mathbf{c}$. On the other hand, the $(Z)$-isomers $\mathbf{2 b}, \mathbf{3 b}$ and $\mathbf{4 b}$ were found to be only weakly active against rat enzyme.

In the case of the $(E)$-isomers, we assume that the double bonds holds the carboxyl groups in a position favorable for interaction with the enzyme, and conversely that the spatial positions of the carboxyl groups of the $(Z)$-isomers are unfavorable. Since the activities of $\mathbf{1 a}-\mathbf{c}$ and the $(E)$-isomers $\mathbf{2 a}$, 3a and $\mathbf{4 a}$ are almost identical, the active conformation of the 4,1-benzoxazepine-3-acetic acid derivatives is presumed be similar to the folded conformation of the $(E)$-(4,1-benzoxazepin-3-ylidene)acetic acid derivatives. ${ }^{10)}$ However, since all compounds described in this paper are racemates, it is not clear which enantiomer is the active inhibitor, and optical resolution of these compounds is currently in progress and will be reported in due course.

\section{Conclusion}

The $(E)$ - and (Z)-(4,1-benzoxazepin-3-ylidene)acetic acid derivatives $2-\mathbf{4}$ were prepared and evaluated for their inhibition of squalene synthase. Interestingly, the $(E)$-isomers were much more potent than the $(Z)$-isomers against rat enzyme, and exhibited equivalent potency to the 4,1-benzoxazepine-3acetic acid derivatives. Thus we assume that the active conformation of the 4,1-benzoxazepine-3-acetic acid derivatives is similar to the folded conformation of the $(E)$-(4,1-benzoxazepin-3-ylidene)acetic acid derivatives. 


\section{Experimental}

All melting points were determined on a Yanagimoto micro melting point apparatus and are uncorrected. Proton nuclear magnetic resonance $\left({ }^{1} \mathrm{H}-\right.$ NMR) spectra were recorded on a Varian GEMINI-200 (200 MHz) spectrometer (with tetramethylsilane as an internal standard). Infrared (IR) absorption spectra were recorded on a JASCO IR-810. $[\alpha]_{\mathrm{D}}$ values were determined in the indicated solvents on a JASCO DIP-370 polarimeter. TLC analyses were carried out on Merck Kieselgel $60 \mathrm{~F}_{254}$ plates. Elemental analyses were carried out by Takeda Analytical Laboratories, Ltd., and are within $\pm 0.4 \%$ of the theoretical values. For column chromatography, Merck Kieselgel 60 (70-230 mesh ASTM) was used. Yields were not maximized. The following abbreviations are used: $\mathrm{s}=$ singlet, $\mathrm{d}=$ doublet, $\mathrm{t}=$ triplet, $\mathrm{q}=$ quartet, $\mathrm{m}=$ multiplet, $\mathrm{br}=$ broad.

Ethyl (2,3-trans)-3-[ $N$-[4-Chloro-2-(2-chloro- $\alpha$-hydroxybenzyl)phenyl]$N$-isopropyl]carbamoyl]-2,3-epoxybutyrate (6a) A mixture of DL-trans-2,3epoxysuccinic acid monoethyl ester ${ }^{3)}(3.1 \mathrm{~g}, 19.3 \mathrm{mmol})$ and dichloromethylenedimethyliminium chloride $(3.14 \mathrm{~g}, 19.3 \mathrm{mmol})$ in $\mathrm{CH}_{2} \mathrm{Cl}_{2}(90 \mathrm{ml})$ was stirred for $1 \mathrm{~h}$ with ice-cooling, followed by addition of $( \pm)-5 \mathrm{a}(4.0 \mathrm{~g}, 12.9$ $\mathrm{mmol})$ and $\mathrm{NaHCO}_{3}(5.42 \mathrm{~g}, 64.5 \mathrm{mmol})$. The solution was stirred for $1 \mathrm{~h}$ at $0{ }^{\circ} \mathrm{C}$, washed with water, dried over $\mathrm{MgSO}_{4}$, and then concentrated in vacuo. The residue was chromatographed [eluent: hexane-AcOEt $(2: 1)$ ] to give $6 a$ $(5.6 \mathrm{~g}, 12.4 \mathrm{mmol}, 96 \%)$ as a colorless powder. $\mathrm{mp} 143-146{ }^{\circ} \mathrm{C}(\mathrm{AcOEt}-$ hexane). IR $v_{\max }(\mathrm{KBr}) \mathrm{cm}^{-1}: 3450,3380(\mathrm{NH}, \mathrm{OH}) ; 1750,1660(\mathrm{C}=\mathrm{O})$. ${ }^{1} \mathrm{H}-\mathrm{NMR}\left(\mathrm{CDCl}_{3}\right) \delta: 0.95-1.5(9 \mathrm{H}, \mathrm{m}), 2.5-3.9(3 \mathrm{H}, \mathrm{m}), 4.0-4.6(3 \mathrm{H}$, m), 6.25-6.6 (1H, m), 6.95-7.8 (7H, m). Anal. Calcd for $\mathrm{C}_{22} \mathrm{H}_{23} \mathrm{Cl}_{2} \mathrm{NO}_{5}$ : C, 58.42; H, 5.13; N, 3.10. Found: C, 58.55; H, 5.31; N, 3.12.

Ethyl (3RS,5SR, $\alpha S R)$-7-Chloro-5-(2-chlorophenyl)-1-isopropyl-2-oxo1,2,3,5-tetrahydro-4,1-benzoxazepine-3-glycolate (7a) and Ethyl (3RS, $5 R S, \alpha S R$ )-7-Chloro-5-(2-chlorophenyl)-1-isopropyl-2-oxo-1,2,3,5-tetrahydro-4,1-benzoxazepine-3-glycolate (7b) A mixture of $\mathbf{6 a}(10.0 \mathrm{~g}, 22.1$ $\mathrm{mmol}), \mathrm{K}_{2} \mathrm{CO}_{3}(3.06 \mathrm{~g}, 2.21 \mathrm{mmol})$ and $\mathrm{EtOH}(200 \mathrm{ml})$ was stirred overnight at room temperature. The reaction mixture was diluted with water, extracted with AcOEt. The extract was washed with brine, dried over $\mathrm{MgSO}_{4}$, and then concentrated under reduced pressure. The residue was chromatographed [eluent: hexane-AcOEt $(2: 1)$ ] to give a $1: 1$ mixture of $7 \mathbf{a}$ and $7 \mathbf{b}$ $(7.2 \mathrm{~g}, 15.9 \mathrm{mmol}, 72 \%)$. The mixture was recrystallized from AcOEthexane to give the $(3 R S, 5 S R, \alpha S R)$-isomer $7 \mathbf{a}(1.75 \mathrm{~g}, 3.87 \mathrm{mmol}, 24 \%)$ as colorless prisms. mp $188-189^{\circ} \mathrm{C}$ (AcOEt-hexane). ${ }^{1} \mathrm{H}-\mathrm{NMR}\left(\mathrm{CDCl}_{3}\right) \delta$ : $1.29(3 \mathrm{H}, \mathrm{t}, J=7.1 \mathrm{~Hz}), 1.30(3 \mathrm{H}, \mathrm{d}, J=7.0 \mathrm{~Hz}), 1.56(3 \mathrm{H}, \mathrm{d}, J=7.0 \mathrm{~Hz}), 4.07$ $(1 \mathrm{H}, \mathrm{d}, J=9.0 \mathrm{~Hz}), 4.19(1 \mathrm{H}, \mathrm{d}, J=4.8 \mathrm{~Hz}), 4.26(2 \mathrm{H}, \mathrm{dq}, J=7.1,1.8 \mathrm{~Hz})$, $4.5-4.65(1 \mathrm{H}, \mathrm{m}), 4.7-4.9(1 \mathrm{H}, \mathrm{m}), 6.04(1 \mathrm{H}, \mathrm{s}), 6.54(1 \mathrm{H}, \mathrm{d}, J=2.6 \mathrm{~Hz})$, $7.2-7.8(6 \mathrm{H}, \mathrm{m})$.

Mother liquid was concentrated in vacuo. The residue was recrystallized from AcOEt-hexane to give the $(3 R S, 5 R S, \alpha S R)$-isomer $7 \mathbf{b}(1.2 \mathrm{~g}, 2.65$ mmol, $17 \%$ ) as colorless prisms. mp $141-142{ }^{\circ} \mathrm{C}$ (AcOEt-hexane). ${ }^{1} \mathrm{H}-$ $\operatorname{NMR}\left(\mathrm{CDCl}_{3}\right) \delta: 0.4-0.6(3 \mathrm{H}, \mathrm{m}), 1.24(3 \mathrm{H}, \mathrm{d}, J=7.4 \mathrm{~Hz}), 1.26(3 \mathrm{H}, \mathrm{t}, J=$ $7.4 \mathrm{~Hz}), 3.95-4.25(2 \mathrm{H}, \mathrm{m}), 4.23(2 \mathrm{H}, \mathrm{q}, J=7.4 \mathrm{~Hz}), 4.38(1 \mathrm{H}, \mathrm{d}, J=$ $5.0 \mathrm{~Hz}), 4.4-4.6(1 \mathrm{H}, \mathrm{m}), 6.09(1 \mathrm{H}, \mathrm{s}), 7.1-7.85(7 \mathrm{H}, \mathrm{m})$.

Ethyl (3RS,5SR, $\alpha S R)$ - $\alpha$-Methanesulfonyloxy-7-chloro-5-(2chlorophenyl)-1-isopropyl-2-oxo-1,2,3,5-tetrahydro-4,1-benzoxazepine3-acetate (8a) and Ethyl (3RS,5RS, $\alpha S R)$ - $\alpha$-Methanesulfonyloxy-7chloro-5-(2-chlorophenyl)-1-isopropyl-2-oxo-1,2,3,5-tetrahydro-4,1-benzoxazepine-3-acetate (8b) $\mathrm{MsCl}(0.13 \mathrm{ml}, 1.72 \mathrm{mmol})$ and $\mathrm{Et}_{3} \mathrm{~N}(0.24 \mathrm{ml}$, $1.72 \mathrm{mmol})$ was added to a solution of $7 \mathbf{a}(0.6 \mathrm{~g}, 1.33 \mathrm{mmol})$ in AcOEt $(30 \mathrm{ml})$ with ice-cooling. After stirring for $1 \mathrm{~h}$, the reaction mixture was washed with brine, dried over $\mathrm{MgSO}_{4}$, and then concentrated. The residue was chromatographed [eluent: hexane- $\mathrm{CH}_{2} \mathrm{Cl}_{2}-\mathrm{AcOEt}(10: 5: 1)$ ] to give 8a $(0.63 \mathrm{~g}, 1.19 \mathrm{mmol}, 89 \%)$ as colorless prisms. $\mathrm{mp} 159-160^{\circ} \mathrm{C}$ (hexaneAcOEt). IR $v_{\max }(\mathrm{KBr}) \mathrm{cm}^{-1}: 1745,1680(\mathrm{C}=\mathrm{O}) .{ }^{1} \mathrm{H}-\mathrm{NMR}\left(\mathrm{CDCl}_{3}\right) \delta: 1.31$ $(3 \mathrm{H}, \mathrm{t}, J=7.1 \mathrm{~Hz}), 1.31(3 \mathrm{H}, \mathrm{d}, J=7.0 \mathrm{~Hz}), 1.56(3 \mathrm{H}, \mathrm{d}, J=7.0 \mathrm{~Hz}), 3.17(3 \mathrm{H}$, s), $4.18(1 \mathrm{H}, \mathrm{d}, J=8.0 \mathrm{~Hz}), 4.32(2 \mathrm{H}, \mathrm{q}, J=7.1 \mathrm{~Hz}), 4.7-4.9(1 \mathrm{H}, \mathrm{m}), 5.37$ $(1 \mathrm{H}, \mathrm{d}, J=8.0 \mathrm{~Hz}), 6.04(1 \mathrm{H}, \mathrm{s}), 6.50(1 \mathrm{H}, \mathrm{d}, J=2.4 \mathrm{~Hz}), 7.2-7.6(6 \mathrm{H}, \mathrm{m})$. Anal. Calcd for $\mathrm{C}_{23} \mathrm{H}_{25} \mathrm{Cl}_{2} \mathrm{NO}_{7} \mathrm{~S}$ : C, 52.08; H, 4.75; N, 2.64. Found: $\mathrm{C}$, $52.25 ; \mathrm{H}, 4.80 ; \mathrm{N}, 2.74$.

Compound $\mathbf{8 b}(0.82 \mathrm{~g}, 1.55 \mathrm{mmol}, 88 \%)$ was prepared from $7 \mathbf{b}(0.80 \mathrm{~g}$, $1.77 \mathrm{mmol}$ ) in a similar manner as described for the preparation of $8 \mathbf{a}$ as a colorless prisms. $\mathrm{mp} 143-144^{\circ} \mathrm{C}$ (AcOEt-hexane). IR $v_{\max }(\mathrm{KBr}) \mathrm{cm}^{-1}$ : 1750, $1670(\mathrm{C}=\mathrm{O}) .{ }^{1} \mathrm{H}-\mathrm{NMR}\left(\mathrm{CDCl}_{3}\right) \delta: 0.5-0.8(3 \mathrm{H}, \mathrm{m}), 1.26(3 \mathrm{H}, \mathrm{d}, J=$ $6.8 \mathrm{~Hz}), 1.29(3 \mathrm{H}, \mathrm{t}, J=7.0 \mathrm{~Hz}), 3.16(3 \mathrm{H}, \mathrm{s}), 4.28(2 \mathrm{H}, \mathrm{q}, J=7.0 \mathrm{~Hz}), 4.1-$ $4.35(1 \mathrm{H}, \mathrm{m}), 4.45-4.6(1 \mathrm{H}, \mathrm{m}), 5.1-5.4(1 \mathrm{H}, \mathrm{m}), 6.09(1 \mathrm{H}, \mathrm{s}), 7.1-7.75$ $(7 \mathrm{H}, \mathrm{m})$. Anal. Calcd for $\mathrm{C}_{23} \mathrm{H}_{25} \mathrm{Cl}_{2} \mathrm{NO}_{7} \mathrm{~S}: \mathrm{C}, 52.08 ; \mathrm{H}, 4.75 ; \mathrm{N}, 2.64$. Found: C, 52.38; H, 4.89; N, 2.77.

Ethyl (E)-[7-Chloro-5-(2-chlorophenyl)-1-isopropyl-2-oxo-1,5-dihydro4,1-benzoxazepin-3(2H)-ylidene]acetate (9a) and Ethyl $(Z)$-[7-Chloro-5-
(2-chlorophenyl)-1-isopropyl-2-oxo-1,5-dihydro-4,1-benzoxazepin-3(2H)ylidene]acetate (9b) A mixture of propionic acid $(0.23 \mathrm{~g}, 3.11 \mathrm{mmol})$ and $\mathrm{Cs}_{2} \mathrm{CO}_{3}(0.34 \mathrm{~g}, 1.04 \mathrm{mmol})$ in $\mathrm{MeOH}(10 \mathrm{ml})$ was stirred for $30 \mathrm{~min}$ at room temperature, and then concentrated under reduced pressure to give cesium propionate as a colorless powder. A mixture of $8 \mathbf{a}(1.0 \mathrm{~g}, 1.89 \mathrm{mmol})$ and cesium propionate in $N, N$-dimethylformamide (DMF, $10 \mathrm{ml}$ ) was stirred for $2 \mathrm{~h}$ at $80^{\circ} \mathrm{C}$, diluted with water, and extracted with AcOEt. The extract was washed with $1 \mathrm{~N} \mathrm{HCl}$ and saturated $\mathrm{NaHCO}_{3}$, dried over $\mathrm{MgSO}_{4}$, and then concentrated in vacuo. The residue was chromatographed [eluent: hexane-AcOEt $(10: 1$ then $5: 1)]$ to give $9 \mathrm{~b}(0.31 \mathrm{~g}, 0.714 \mathrm{mmol}, 38 \%)$ as colorless prisms from the first fraction and $9 \mathrm{a}(0.13 \mathrm{~g}, 0.299 \mathrm{mmol}, 16 \%)$ as a colorless prisms from the second fraction.

9a: $\mathrm{mp} 143-144^{\circ} \mathrm{C}\left(\mathrm{Et}_{2} \mathrm{O}-\right.$ hexane). IR $v_{\max }(\mathrm{KBr}) \mathrm{cm}^{-1}: 1710,1670$ $(\mathrm{C}=\mathrm{O}), 1650(\mathrm{C}=\mathrm{C}) .{ }^{1} \mathrm{H}-\mathrm{NMR}\left(\mathrm{CDCl}_{3}\right) \delta: 1.23(3 \mathrm{H}, \mathrm{t}, J=7.2 \mathrm{~Hz}), 1.34$ $(3 \mathrm{H}, \mathrm{d}, J=7.0 \mathrm{~Hz}), 1.66(3 \mathrm{H}, \mathrm{d}, J=7.0 \mathrm{~Hz}), 4.05-4.3(2 \mathrm{H}, \mathrm{m}), 4.9-5.1$ $(1 \mathrm{H}, \mathrm{m}), 5.41(1 \mathrm{H}, \mathrm{s}), 6.49(1 \mathrm{H}, \mathrm{s}), 6.53(1 \mathrm{H}, \mathrm{s}), 7.3-7.6(5 \mathrm{H}, \mathrm{m}), 7.78(1 \mathrm{H}$, d, $J=6.8 \mathrm{~Hz}$ ). Anal. Calcd for $\mathrm{C}_{22} \mathrm{H}_{21} \mathrm{Cl}_{2} \mathrm{NO}_{4}: \mathrm{C}, 60.84 ; \mathrm{H}, 4.87 ; \mathrm{N}, 3.22$. Found: C, $60.59 ; \mathrm{H}, 4.84 ; \mathrm{N}, 3.30$.

9b: $\mathrm{mp} 194-195^{\circ} \mathrm{C}\left(\mathrm{Et}_{2} \mathrm{O}-\right.$ hexane $)$. IR $v_{\max }(\mathrm{KBr}) \mathrm{cm}^{-1}: 1700,1650$ $(\mathrm{C}=\mathrm{O}), 1630(\mathrm{C}=\mathrm{C}) .{ }^{1} \mathrm{H}-\mathrm{NMR}\left(\mathrm{CDCl}_{3}\right) \delta: 1.27(3 \mathrm{H}, \mathrm{t}, J=7.0 \mathrm{~Hz}), 1.30$ $(3 \mathrm{H}, \mathrm{d}, J=6.8 \mathrm{~Hz}), 1.61(3 \mathrm{H}, \mathrm{d}, J=6.8 \mathrm{~Hz}), 4.05-4.3(2 \mathrm{H}, \mathrm{m}), 4.7-4.95$ $(1 \mathrm{H}, \mathrm{m}), 5.48(1 \mathrm{H}, \mathrm{s}), 6.52(1 \mathrm{H}, \mathrm{s}), 6.57(1 \mathrm{H}, \mathrm{d}, J=2.2 \mathrm{~Hz}), 7.3-7.6(5 \mathrm{H}$, m), $8.16(1 \mathrm{H}, \mathrm{d}, J=7.4 \mathrm{~Hz})$. Anal. Calcd for $\mathrm{C}_{22} \mathrm{H}_{21} \mathrm{Cl}_{2} \mathrm{NO}_{4}: \mathrm{C}, 60.84 ; \mathrm{H}$, 4.87; N, 3.22. Found: C, 60.76; H, 4.99; N, 3.32.

$8 \mathbf{b}(1.0 \mathrm{~g}, 1.89 \mathrm{mmol})$ was converted to a mixture of $9 \mathbf{a}$ and $9 \mathbf{b}$ in a similar manner as described above. The mixture was chromatographed [eluent: hexane-AcOEt $(10: 1-5: 1)]$ to give $9 \mathbf{b}(0.33 \mathrm{~g}, 0.760 \mathrm{mmol}, 40 \%)$ as colorless prisms from the first fraction and $9 \mathrm{a}(0.17 \mathrm{~g}, 0.391 \mathrm{mmol}, 21 \%)$ as a colorless prisms from the second fraction.

(E)-[7-Chloro-5-(2-chlorophenyl)-1-isopropyl-2-oxo-1,5-dihydro-4,1benzoxazepin-3(2H)-ylidene]acetic Acid (2a) and (Z)-[7-Chloro-5-(2chlorophenyl)-1-isopropyl-2-oxo-1,5-dihydro-4,1-benzoxazepin-3(2H)ylidene]acetic Acid (2b) One normal $\mathrm{NaOH}(5 \mathrm{ml})$ was added to a solution of 9a $(0.16 \mathrm{~g}, 0.368 \mathrm{mmol})$ in $\mathrm{MeOH}(20 \mathrm{ml})$. The mixture was stirred for $1 \mathrm{~h}$ at room temperature, diluted with water, acidified, and extracted with AcOEt. The extract was washed with brine, dried over $\mathrm{MgSO}_{4}$, and then concentrated under reduced pressure to give $2 \mathrm{a}(0.14 \mathrm{~g}, 0.345 \mathrm{mmol}, 94 \%)$ as colorless plates.

Compound $2 \mathbf{b}(0.26 \mathrm{~g}, 0.640 \mathrm{mmol}, 93 \%)$ was prepared from $9 \mathbf{b}(0.3 \mathrm{~g}$, $0.691 \mathrm{mmol}$ ) in a similar manner as described for the preparation of $\mathbf{2 a}$ as a colorless plates.

2a: $\mathrm{mp} 209-214^{\circ} \mathrm{C}$ (dec.) (AcOEt-hexane). IR $v_{\max }(\mathrm{KBr}) \mathrm{cm}^{-1}: 1720$, $1650(\mathrm{C}=\mathrm{O}), 1630(\mathrm{C}=\mathrm{C}) .{ }^{1} \mathrm{H}-\mathrm{NMR}\left(\mathrm{CDCl}_{3}\right) \delta: 1.34(3 \mathrm{H}, \mathrm{d}, J=7.0 \mathrm{~Hz})$, $1.62(3 \mathrm{H}, \mathrm{d}, J=7.0 \mathrm{~Hz}), 4.8-5.0(1 \mathrm{H}, \mathrm{m}), 5.41(1 \mathrm{H}, \mathrm{s}), 6.51(1 \mathrm{H}, \mathrm{s}), 6.54$ $(1 \mathrm{H}, \mathrm{d}, J=1.8 \mathrm{~Hz}), 7.3-7.6(5 \mathrm{H}, \mathrm{m}), 7.78(1 \mathrm{H}, \mathrm{d}, J=7.0 \mathrm{~Hz})$. Anal. Calcd for $\mathrm{C}_{20} \mathrm{H}_{17} \mathrm{Cl}_{2} \mathrm{NO}_{4}$ : C, 59.13; H, 4.22; N, 3.45. Found: C, 58.97; H, 4.24; N, 3.42 .

2b: $\mathrm{mp} 234-239^{\circ} \mathrm{C}$ (dec.) (AcOEt-hexane). IR $v_{\max }(\mathrm{KBr}) \mathrm{cm}^{-1}: 1670$ $(\mathrm{C}=\mathrm{O}), 1655(\mathrm{C}=\mathrm{C}) .{ }^{1} \mathrm{H}-\mathrm{NMR}\left(\mathrm{CDCl}_{3}\right) \delta: 1.31(3 \mathrm{H}, \mathrm{d}, J=7.0 \mathrm{~Hz}), 1.61$ $(3 \mathrm{H}, \mathrm{d}, J=7.0 \mathrm{~Hz}), 4.7-4.9(1 \mathrm{H}, \mathrm{m}), 5.48(1 \mathrm{H}, \mathrm{s}), 6.54(1 \mathrm{H}, \mathrm{s}), 6.57(1 \mathrm{H}, \mathrm{d}$, $J=2.2 \mathrm{~Hz}), 7.3-7.6(5 \mathrm{H}, \mathrm{m}), 8.05(1 \mathrm{H}, \mathrm{d}, J=7.8 \mathrm{~Hz})$. Anal. Calcd for $\mathrm{C}_{20} \mathrm{H}_{17} \mathrm{Cl}_{2} \mathrm{NO}_{4}: \mathrm{C}, 59.13 ; \mathrm{H}, 4.22 ; \mathrm{N}, 3.45$. Found: $\mathrm{C}, 59.02 ; \mathrm{H}, 4.21 ; \mathrm{N}$, 3.37 .

Ethyl (2,3-trans)-3-[ $N$-[4-Chloro-2-(2-chloro- $\alpha$-hydroxybenzyl)phenyl]$N$-propyl]carbamoyl]-2,3-epoxybutyrate (6b) and Ethyl (2,3-trans)-3-[N[4-Chloro-2-(2-chloro- $\alpha$-hydroxybenzyl)phenyl]- $N$-isobutyl]carbamoyl]2,3-epoxybutyrate (6c) Compound $\mathbf{6 b}(5.3 \mathrm{~g}, 11.7 \mathrm{mmol}, 91 \%)$ and $\mathbf{6 c}$ $(14.0 \mathrm{~g}, 30.0 \mathrm{mmol}, 97 \%)$ were prepared from $( \pm)-5 \mathbf{b}(4.0 \mathrm{~g}, 12.9 \mathrm{mmol})$ and $( \pm)-5 \mathbf{c}(10.0 \mathrm{~g}, 30.8 \mathrm{mmol})$ in a similar manner as described for the preparation of $\mathbf{6 a}$.

6b: An oil. IR $v_{\max }$ (neat) $\mathrm{cm}^{-1}: 1745,1660(\mathrm{C}=\mathrm{O}) .{ }^{1} \mathrm{H}-\mathrm{NMR}\left(\mathrm{CDCl}_{3}\right) \delta$ : $0.75-1.05(3 \mathrm{H}, \mathrm{m}), 1.1-1.8(5 \mathrm{H}, \mathrm{m}), 2.6-3.9(4 \mathrm{H}, \mathrm{m}), 4.0-4.5(3 \mathrm{H}, \mathrm{m})$, $6.1-6.4(1 \mathrm{H}, \mathrm{m}), 6.9-7.9(7 \mathrm{H}, \mathrm{m})$.

6c: An oil. IR $v_{\max }$ (neat) $\mathrm{cm}^{-1}: 3390(\mathrm{OH}) ; 1745,1660(\mathrm{C}=\mathrm{O}) .{ }^{1} \mathrm{H}-\mathrm{NMR}$ $\left(\mathrm{CDCl}_{3}\right) \delta: 0.75-1.05(6 \mathrm{H}, \mathrm{m}), 1.15-1.4(3 \mathrm{H}, \mathrm{m}), 1.7-2.0(1 \mathrm{H}, \mathrm{m}), 2.7-$ $3.3(2 \mathrm{H}, \mathrm{m}), 3.3-3.9(2 \mathrm{H}, \mathrm{m}), 4.0-4.45(3 \mathrm{H}, \mathrm{m}), 6.1-6.4(1 \mathrm{H}, \mathrm{m}), 7.0-$ $7.8(7 \mathrm{H}, \mathrm{m})$.

Ethyl (3,5-trans)-7-Chloro-5-(2-chlorophenyl)-2-oxo-1-propyl-1,2,3,5tetrahydro-4,1-benzoxazepine-3-glycolate (10a) and Ethyl (3,5-trans)-7Chloro-5-(2-chlorophenyl)-1-isobutyl-2-oxo-1,2,3,5-tetrahydro-4,1-benzoxazepine-3-glycolate (10b) A mixture of $\mathbf{6 c}(13.0 \mathrm{~g}, 27.9 \mathrm{mmol})$ and $\mathrm{K}_{2} \mathrm{CO}_{3}(3.85 \mathrm{~g}, 27.9 \mathrm{mmol})$ in $\mathrm{EtOH}(150 \mathrm{ml})$ was stirred overnight at room temperature, diluted with water, and extracted with AcOEt. The extract was washed with brine, dried over $\mathrm{MgSO}_{4}$, and then concentrated. The residue 
was chromatographed [eluent: hexane-AcOEt $(2: 1)$ ] to give 10b (a mixture of diastereomers) (7.0 g, $15.0 \mathrm{mmol}, 54 \%$ ) as colorless crystals.

10b: IR $v_{\max }(\mathrm{KBr}) \mathrm{cm}^{-1}: 3400(\mathrm{OH}) ; 1740,1670,1640(\mathrm{C}=\mathrm{O}) .{ }^{1} \mathrm{H}-\mathrm{NMR}$ $\left(\mathrm{CDCl}_{3}\right) \delta: 0.7-1.1(6 \mathrm{H}, \mathrm{m}), 1.2-1.4(5 \mathrm{H}, \mathrm{m}), 1.7-2.1(1 \mathrm{H}, \mathrm{m}), 3.35-$ $4.0(2 \mathrm{H}, \mathrm{m}), 4.0-4.8(5 \mathrm{H}, \mathrm{m}), 6.15,6.19(1 \mathrm{H}$, each s, $c a .1: 1), 6.55,6.96$ $(1 \mathrm{H}$, each d, $J=2.4 \mathrm{~Hz}), 7.15-7.8(6 \mathrm{H}, \mathrm{m})$. Anal. Calcd for $\mathrm{C}_{23} \mathrm{H}_{25} \mathrm{Cl}_{2} \mathrm{NO}_{5}$ : C, 59.24; H, 5.40; N, 3.00. Found:C, 59.14; H, 5.37; N, 2.98 .

Compound 10a $(2.3 \mathrm{~g}, 5.08 \mathrm{mmol}, 43 \%)$ was prepared from $\mathbf{6 b}(5.3 \mathrm{~g}$, $11.7 \mathrm{mmol}$ ) in a similar manner as described for the preparation of $\mathbf{1 0 b}$.

10a: An oil. IR $v_{\max }(\mathrm{KBr}) \mathrm{cm}^{-1}: 3380(\mathrm{OH}) ; 1745,1650(\mathrm{C}=\mathrm{O}) .{ }^{1} \mathrm{H}-$ $\operatorname{NMR}\left(\mathrm{CDCl}_{3}\right) \delta: 0.7-1.05(3 \mathrm{H}, \mathrm{m}), 1.15-1.4(3 \mathrm{H}, \mathrm{m}), 1.45-1.8(2 \mathrm{H}, \mathrm{m})$, $3.4-3.9(2 \mathrm{H}, \mathrm{m}), 4.0-4.7(4 \mathrm{H}, \mathrm{m}), 6.08,6.10(1 \mathrm{H}$, each s$), 6.5-7.8(7 \mathrm{H}$, m). Anal. Calcd for $\mathrm{C}_{22} \mathrm{H}_{23} \mathrm{Cl}_{2} \mathrm{NO}_{5}: \mathrm{C}, 58.42 ; \mathrm{H}, 5.12 ; \mathrm{N}, 3.10$. Found : C, $58.40 ; \mathrm{H}, 5.23 ; \mathrm{N}, 3.01$.

Ethyl $\alpha$-Methanesulfonyloxy-(3,5-trans)-7-chloro-5-(2-chlorophenyl)2-oxo-1-propyl-1,2,3,5-tetrahydro-4,1-benzoxazepine-3-acetate (11a) and Ethyl $\alpha$-Methanesulfonyloxy-(3,5-trans)-7-chloro-5-(2-chlorophenyl)-1isobutyl-2-oxo-1,2,3,5-tetrahydro-4,1-benzoxazepine-3-acetatel (11b) Compounds 11a $(1.9 \mathrm{~g}, 3.58 \mathrm{mmol}, 81 \%)$ and $11 \mathrm{~b}(2.0 \mathrm{~g}, 3.67 \mathrm{mmol}, 95 \%)$ were prepared from $10 \mathrm{a}(2.0 \mathrm{~g}, 4.42 \mathrm{mmol})$ and $\mathbf{1 0 b}(1.8 \mathrm{~g}, 3.86 \mathrm{mmol})$ in a similar manner as described for the preparation of $\mathbf{8 a}$.

11a: An oil. IR $v_{\max }$ (neat) $\mathrm{cm}^{-1}: 1750,1670(\mathrm{C}=\mathrm{O}) .{ }^{1} \mathrm{H}-\mathrm{NMR}\left(\mathrm{CDCl}_{3}\right)$ $\delta: 0.7-1.1(3 \mathrm{H}, \mathrm{m}), 1.2-1.4(3 \mathrm{H}, \mathrm{m}), 1.5-1.85(2 \mathrm{H}, \mathrm{m}), 3.07,3.16(3 \mathrm{H}$, each s), 3.4-3.8 $(2 \mathrm{H}, \mathrm{m}), 4.2-5.45(4 \mathrm{H}, \mathrm{m}), 6.07,6.10(1 \mathrm{H}$, each s$), 6.5-$ $7.7(7 \mathrm{H}, \mathrm{m})$.

11b: A mixture of crystals and an oil. IR $v_{\max }$ (Nujol) $\mathrm{cm}^{-1}: 1765,1670$, $1630(\mathrm{C}=\mathrm{O}) .{ }^{1} \mathrm{H}-\mathrm{NMR}\left(\mathrm{CDCl}_{3}\right) \delta: 0.75-1.1(6 \mathrm{H}, \mathrm{m}), 1.25-1.4(3 \mathrm{H}, \mathrm{m})$, $1.7-2.1(1 \mathrm{H}, \mathrm{m}), 2.98,3.16(3 \mathrm{H}$, each s$), 3.35-3.6(1 \mathrm{H}, \mathrm{m}), 3.9-5.5(5 \mathrm{H}$, m), $6.18(1 \mathrm{H}, \mathrm{s}), 6.5-7.85(7 \mathrm{H}, \mathrm{m})$. Anal. Calcd for $\mathrm{C}_{24} \mathrm{H}_{27} \mathrm{Cl}_{2} \mathrm{NO}_{7} \mathrm{~S}: \mathrm{C}$, $52.95 ; \mathrm{H}, 5.00 ; \mathrm{N}, 2.57$. Found: C, 52.92; H, 5.07; N, 2.72

Ethyl $(E)$ - and $(Z)$-[7-Chloro-5-(2-chlorophenyl)-2-oxo-1-propyl-1,5dihydro-4,1-benzoxazepin-3(2H)-ylidenejacetate $(12 \mathrm{a}, \mathrm{b})$ and Ethyl $(E)$ and (Z)-[7-Chloro-5-(2-chlorophenyl)-1-isobutyl-2-oxo-1,5-dihydro-4,1benzoxazepine-3(2H)-ylidene]acetate $(13 \mathbf{a}, \mathbf{b})$ Compounds 12a,b and 13a, b were prepared from 11a $(1.9 \mathrm{~g}, 3.58 \mathrm{mmol})$ and $11 \mathbf{b}(2.0 \mathrm{~g}, 3.67$ $\mathrm{mmol})$ in a similar manner as described for the preparation of $\mathbf{9 a}, \mathbf{b}$.

12a (Polar): Prisms. Yield $0.20 \mathrm{~g}(0.461 \mathrm{mmol}, 13 \%) . \mathrm{mp} 114-115^{\circ} \mathrm{C}$ (Et $\mathrm{Et}_{2} \mathrm{O}$-hexane). IR $v_{\max }(\mathrm{KBr}) \mathrm{cm}^{-1}: 1715,1670(\mathrm{C}=\mathrm{O}), 1640(\mathrm{C}=\mathrm{C}) .{ }^{1} \mathrm{H}-$ NMR $\left(\mathrm{CDCl}_{3}\right) \delta: 1.00(3 \mathrm{H}, \mathrm{t}, J=7.4 \mathrm{~Hz}), 1.27(3 \mathrm{H}, \mathrm{t}, J=7.1 \mathrm{~Hz}), 1.5-1.9$ $(2 \mathrm{H}, \mathrm{m}), 3.5-3.75(1 \mathrm{H}, \mathrm{m}), 4.13(2 \mathrm{H}, \mathrm{q}, J=7.1 \mathrm{~Hz}), 4.3-4.55(1 \mathrm{H}, \mathrm{m})$, $5.45(1 \mathrm{H}, \mathrm{s}), 6.49(1 \mathrm{H}, \mathrm{s}), 6.53(1 \mathrm{H}, \mathrm{d}, J=1.8 \mathrm{~Hz}), 7.3-7.6(5 \mathrm{H}, \mathrm{m}), 7.78$ $(1 \mathrm{H}, \mathrm{d}, J=6.6 \mathrm{~Hz})$. Anal. Calcd for $\mathrm{C}_{22} \mathrm{H}_{21} \mathrm{Cl}_{2} \mathrm{NO}_{4}: \mathrm{C}, 60.84 ; \mathrm{H}, 4.87 ; \mathrm{N}$, 3.22. Found: C, $60.85 ; \mathrm{H}, 5.17 ; \mathrm{N}, 3.13$.

12b (Less Polar): Prisms. Yield $0.61 \mathrm{~g}(1.40 \mathrm{mmol}, 39 \%)$. mp $171-$ $172{ }^{\circ} \mathrm{C}\left(\mathrm{Et}_{2} \mathrm{O}-\right.$-hexane $) . \quad \mathrm{IR} \quad v_{\max }(\mathrm{KBr}) \mathrm{cm}^{-1}: 1710,1660(\mathrm{C}=\mathrm{O}), 1630$ $(\mathrm{C}=\mathrm{C}) .{ }^{1} \mathrm{H}-\mathrm{NMR}\left(\mathrm{CDCl}_{3}\right) \delta: 0.98(3 \mathrm{H}, \mathrm{t}, J=7.4 \mathrm{~Hz}), 1.28(3 \mathrm{H}, \mathrm{t}, J=7.1 \mathrm{~Hz})$, $1.6-1.85(2 \mathrm{H}, \mathrm{m}), 3.45-3.7(1 \mathrm{H}, \mathrm{m}), 4.1-4.3(2 \mathrm{H}, \mathrm{m}), 4.4-4.6(1 \mathrm{H}, \mathrm{m})$, $5.50(1 \mathrm{H}, \mathrm{s}), 6.53(1 \mathrm{H}, \mathrm{s}), 6.57(1 \mathrm{H}, \mathrm{d}, J=2.2 \mathrm{~Hz}), 7.2-7.6(5 \mathrm{H}, \mathrm{m}), 8.17$ $(1 \mathrm{H}, \mathrm{d}, J=7.2 \mathrm{~Hz})$. Anal. Calcd for $\mathrm{C}_{22} \mathrm{H}_{21} \mathrm{Cl}_{2} \mathrm{NO}_{4}: \mathrm{C}, 60.84 ; \mathrm{H}, 4.87 ; \mathrm{N}$, 3.22. Found: C, $60.65 ; \mathrm{H}, 4.73 ; \mathrm{N}, 3.15$.

13a (Polar): An oil. Yield $0.29 \mathrm{~g}(0.647 \mathrm{mmol}, 18 \%)$. IR $v_{\max }$ (Neat) $\mathrm{cm}^{-1}: 1710,1670(\mathrm{C}=\mathrm{O}), 1645(\mathrm{C}=\mathrm{C}) .{ }^{1} \mathrm{H}-\mathrm{NMR}\left(\mathrm{CDCl}_{3}\right) \delta: 0.95(3 \mathrm{H}, \mathrm{d}$, $J=6.6 \mathrm{~Hz}), 1.07(3 \mathrm{H}, \mathrm{d}, J=6.6 \mathrm{~Hz}), 1.9-2.2(1 \mathrm{H}, \mathrm{m}), 3.57(1 \mathrm{H}, \mathrm{dd}, J=14.0$, $5.8 \mathrm{~Hz}), 4.0-4.25(2 \mathrm{H}, \mathrm{m}), 4.37(1 \mathrm{H}, \mathrm{dd}, J=14.0,8.6 \mathrm{~Hz}), 5.44(1 \mathrm{H}, \mathrm{s})$, $6.54(1 \mathrm{H}, \mathrm{d}, J=1.8 \mathrm{~Hz}), 6.57(1 \mathrm{H}, \mathrm{s}), 7.3-7.9(6 \mathrm{H}, \mathrm{m})$.

13b (Less Polar): Prisms. Yield $0.89 \mathrm{~g}(1.99 \mathrm{mmol}, 54 \%)$ mp $181-$ $182^{\circ} \mathrm{C}\left(\mathrm{Et}_{2} \mathrm{O}-\right.$ hexane). IR $v_{\max }(\mathrm{KBr}) \mathrm{cm}^{-1}: 1715(\mathrm{C}=\mathrm{O}), 1650(\mathrm{C}=\mathrm{C}) .{ }^{1} \mathrm{H}-$ NMR $\left(\mathrm{CDCl}_{3}\right) \delta: 0.94(3 \mathrm{H}, \mathrm{d}, J=6.6 \mathrm{~Hz}), 1.01(3 \mathrm{H}, \mathrm{d}, J=6.6 \mathrm{~Hz}), 1.85-2.1$ $(1 \mathrm{H}, \mathrm{m}), 3.43(1 \mathrm{H}, \mathrm{dd}, J=13.8,5.6 \mathrm{~Hz}), 4.05-4.25(2 \mathrm{H}, \mathrm{m}), 4.45(1 \mathrm{H}, \mathrm{dd}$, $J=13.8,8.6 \mathrm{~Hz}), 5.51(1 \mathrm{H}, \mathrm{s}), 6.57(1 \mathrm{H}, \mathrm{d}, J=2.4 \mathrm{~Hz}), 6.61(1 \mathrm{H}, \mathrm{s}), 7.2-7.6$ $(5 \mathrm{H}, \mathrm{m}), 8.19(1 \mathrm{H}, \mathrm{d}, J=8.0 \mathrm{~Hz})$. Anal. Calcd for $\mathrm{C}_{23} \mathrm{H}_{23} \mathrm{Cl}_{2} \mathrm{NO}_{4}: \mathrm{C}, 61.62$; H, 5.17; N, 3.12. Found: C, 61.54; H, 5.30; N, 3.09.

(E)- and (Z)-[7-Chloro-5-(2-chlorophenyl)-2-oxo-1-propyl-1,5-dihydro-4,1-benzoxazepin-3-ylidene]acetic Acid (3a,b; Table 1) and Ethyl $(E)$ - and (Z)-[7-Chloro-5-(2-chlorophenyl)-1-isobutyl-2-oxo-1,5-dihydro4,1-benzoxazepin-3-ylidene]acetic Acid (4a,b; Table 1) Compounds 3a, b and $4 \mathbf{a}, \mathbf{b}$ were prepared from 12a $(0.17 \mathrm{~g}, 0.391 \mathrm{mmol}), \mathbf{1 2 b}(0.30 \mathrm{~g}$, $0.691 \mathrm{mmol}), 13 \mathrm{a}(0.28 \mathrm{~g}, 0.625 \mathrm{mmol})$ and $13 \mathrm{~b}(0.30 \mathrm{~g}, 0.669 \mathrm{mmol})$ in a similar manner as described for the preparation of $\mathbf{2 a}, \mathbf{b}$.

3a: Prisms. Yield $0.15 \mathrm{~g}(0.369 \mathrm{mmol}, 94 \%)$. mp $192-194^{\circ} \mathrm{C}$ (dec.) (AcOEt-hexane). IR $v_{\max }(\mathrm{KBr}) \mathrm{cm}^{-1}: 1715,1645(\mathrm{C}=\mathrm{O}), 1635(\mathrm{C}=\mathrm{C})$. ${ }^{1} \mathrm{H}-\mathrm{NMR}\left(\mathrm{CDCl}_{3}\right) \delta: 1.01(3 \mathrm{H}, \mathrm{t}, J=7.4 \mathrm{~Hz}), 1.6-1.9(2 \mathrm{H}, \mathrm{m}), 3.6-3.8$ $(1 \mathrm{H}, \mathrm{m}), 4.25-4.5(1 \mathrm{H}, \mathrm{m}), 5.47(1 \mathrm{H}, \mathrm{s}), 6.51(1 \mathrm{H}, \mathrm{s}), 6.54(1 \mathrm{H}, \mathrm{d}$, $J=2.2 \mathrm{~Hz}), 7.3-7.6(5 \mathrm{H}, \mathrm{m}), 7.80(1 \mathrm{H}, \mathrm{d}, J=6.6 \mathrm{~Hz})$. Anal. Calcd for
$\mathrm{C}_{20} \mathrm{H}_{17} \mathrm{Cl}_{2} \mathrm{NO}_{4}$ : C, 59.13; H, 4.22; N, 3.45. Found: C, 58.88; H, 4.34; N, 3.27 .

3b: Prisms. Yield $0.23 \mathrm{~g}(0.566 \mathrm{mmol}, 82 \%)$. mp $208-210^{\circ} \mathrm{C}$ (dec.) (AcOEt-hexane). IR $v_{\max }(\mathrm{KBr}) \mathrm{cm}^{-1}: 1690,1655(\mathrm{C}=\mathrm{O}), 1635(\mathrm{C}=\mathrm{C})$. ${ }^{1} \mathrm{H}-\mathrm{NMR}\left(\mathrm{CDCl}_{3}\right) \delta: 0.98(3 \mathrm{H}, \mathrm{t}, J=7.4 \mathrm{~Hz}), 1.6-1.9(2 \mathrm{H}, \mathrm{m}), 3.4-3.7$ $(1 \mathrm{H}, \mathrm{m}), 4.4-4.6(1 \mathrm{H}, \mathrm{m}), 5.51(1 \mathrm{H}, \mathrm{s}), 6.56(1 \mathrm{H}, \mathrm{s}), 6.58(1 \mathrm{H}, \mathrm{d}$, $J=2.4 \mathrm{~Hz}), 7.2-7.6(5 \mathrm{H}, \mathrm{m}), 8.07(1 \mathrm{H}, \mathrm{d}, J=7.0 \mathrm{~Hz})$. Anal. Calcd for $\mathrm{C}_{20} \mathrm{H}_{17} \mathrm{Cl}_{2} \mathrm{NO}_{4}$ : C, 59.13; H, 4.22; N, 3.45. Found: C, 59.20; H, 4.39; N, 3.32 .

4a: Prisms. Yield $0.25 \mathrm{~g}(0.595 \mathrm{mmol}, 95 \%)$. mp $207-209^{\circ} \mathrm{C}$ (dec.) (AcOEt-hexane). IR $v_{\max }(\mathrm{KBr}) \mathrm{cm}^{-1}: 1720(\mathrm{C}=\mathrm{O}), 1645(\mathrm{C}=\mathrm{C}) .{ }^{1} \mathrm{H}-\mathrm{NMR}$ $\left(\mathrm{CDCl}_{3}\right) \delta: 0.97(3 \mathrm{H}, \mathrm{d}, J=6.7 \mathrm{~Hz}), 1.08(3 \mathrm{H}, \mathrm{d}, J=6.6 \mathrm{~Hz}), 1.95-2.2(1 \mathrm{H}$, m), $3.63(1 \mathrm{H}, \mathrm{dd}, J=13.9,5.6 \mathrm{~Hz}), 4.23(1 \mathrm{H}, \mathrm{dd}, J=13.9,8.8 \mathrm{~Hz}), 5.46(1 \mathrm{H}$, s), $6.55(1 \mathrm{H}, \mathrm{d}, J=2.2 \mathrm{~Hz}), 6.58(1 \mathrm{H}, \mathrm{s}), 7.3-7.9(6 \mathrm{H}, \mathrm{m})$. Anal. Calcd for $\mathrm{C}_{21} \mathrm{H}_{19} \mathrm{Cl}_{2} \mathrm{NO}_{4}: \mathrm{C}, 60.01 ; \mathrm{H}, 4.56 ; \mathrm{N}, 3.33$. Found: $\mathrm{C}, 59.95 ; \mathrm{H}, 4.64 ; \mathrm{N}$, 3.45 .

4b: Prisms. Yield $0.25 \mathrm{~g}(0.595 \mathrm{mmol}, 89 \%)$. mp $236-238^{\circ} \mathrm{C}$ (dec.) (AcOEt-hexane). IR $v_{\max }(\mathrm{KBr}) \mathrm{cm}^{-1}: 1690,1655(\mathrm{C}=\mathrm{O}), 1630(\mathrm{C}=\mathrm{C})$. ${ }^{1} \mathrm{H}-\mathrm{NMR}\left(\mathrm{CDCl}_{3}\right) \delta: 0.95(3 \mathrm{H}, \mathrm{d}, J=6.6 \mathrm{~Hz}), 1.02(3 \mathrm{H}, \mathrm{d}, J=6.6 \mathrm{~Hz}), 1.85-$ $2.1(1 \mathrm{H}, \mathrm{m}), 3.45(1 \mathrm{H}, \mathrm{dd}, J=13.8,5.8 \mathrm{~Hz}), 4.46(1 \mathrm{H}, \mathrm{dd}, J=13.8,8.6 \mathrm{~Hz})$, $5.52(1 \mathrm{H}, \mathrm{s}), 6.57(1 \mathrm{H}, \mathrm{d}, J=2.2 \mathrm{~Hz}), 6.64(1 \mathrm{H}, \mathrm{s}), 7.2-7.6(5 \mathrm{H}, \mathrm{m})$. Anal. Calcd for $\mathrm{C}_{21} \mathrm{H}_{19} \mathrm{Cl}_{2} \mathrm{NO}_{4}$ : C, 60.01; $\mathrm{H}, 4.56 ; \mathrm{N}, 3.33$. Found: $\mathrm{C}, 60.16 ; \mathrm{H}$, $4.56 ; \mathrm{N}, 3.50$.

Animals and Materials Animals were supplied by Clea, Japan, Inc. unless otherwise mentioned. $R S-\left[2-{ }^{14} \mathrm{C}\right]$ Mevalonolactone and $\left[1-{ }^{3} \mathrm{H}\right]$ farnesyl pyrophosphate were purchased from New England Nuclear. $\left[2-{ }^{14} \mathrm{C}\right] \mathrm{meval}-$ onic acid was synthesized from $\left[2-{ }^{14} \mathrm{C}\right]$ mevalonolactone by saponification with potassium hydroxide. $\left[2{ }^{14} \mathrm{C}\right]$ Sodium acetate was purchased from Amersham. Farnesyl pyrophosphate was synthesized by the method described by V. J. Davisson and coworkers ${ }^{11}$ (Nemoto \& Co.). HepG2 cells were supplied by The American Type Culture Collection (ATCC). Fetal bovine serum (FBS) and Dulbecco's modified Eagle's medium (DMEM) were purchased from GIBCO. Human lipoprotein deficient serum (human LPDS) was purchased from Sigma. All other reagents were supplied by Wako Pure Chemical Industries.

Preparation of Rat Squalene Synthase An Sprague-Dawley (SD) male rat (6-week old) was killed by bleeding, and its liver was excised. About $10 \mathrm{~g}$ of the liver was washed with a saline solution cooled with ice, which was then homogenized in $15 \mathrm{ml}$ of an ice-cooled buffer solution [100 mm potassium phosphate ( $\mathrm{pH} 7.4), 15 \mathrm{~mm}$ nicotinamide, $2 \mathrm{~mm} \mathrm{MgCl}{ }_{2}$ ], followed by centrifugation for $20 \mathrm{~min}$ at $10000 \times \boldsymbol{g}\left(4^{\circ} \mathrm{C}\right)$. The supernatant layer was separated and subjected to further centrifugation for $90 \mathrm{~min}$ at $105000 \times g\left(4^{\circ} \mathrm{C}\right)$. The sediment was then suspended in an ice-cooled 100 mм potassium phosphate buffer solution ( $\mathrm{pH} 7.4)$, which was again subjected to centrifugation for $90 \mathrm{~min}$ at $105000 \times \boldsymbol{g}\left(4^{\circ} \mathrm{C}\right)$. The sediment thus obtained (microsome fraction) was suspended in an ice-cooled $100 \mathrm{~mm}$ potassium phosphate buffer ( $\mathrm{pH}$ 7.4) (about $40 \mathrm{mg} / \mathrm{ml}$ protein concentration, determined using Bicinchoninic acid (BCA) protein assay kit of Pierce Co., Ltd.). This suspension was used as the enzyme solution.

Preparation of Human Squalene Synthase HepG2 cells (about $1 \times 10^{9}$ cells) obtained by incubation $\left(37^{\circ} \mathrm{C}\right.$ in the presence of $\left.5 \% \mathrm{CO}_{2}\right)$ in a DMEM contains $10 \%$ FBS, penicillin $\mathrm{G}(100 \mathrm{units} / \mathrm{ml})$ and streptomycin $(10 \mu \mathrm{g} / \mathrm{ml})$ were suspended in $10 \mathrm{ml}$ of ice-cooled buffer solution [100 mM potassium phosphate buffer ( $\mathrm{pH} 7.4$ ), $30 \mathrm{~mm}$ nicotinamide and $2.5 \mathrm{~mm} \mathrm{MgCl}_{2}$ ]. The cells were crashed by means of ultrasonication (for $30 \mathrm{~s}$, twice). From the sonicate thus obtained, the microsome fraction was obtained by the same procedure as in preparation of rat-derived enzyme, which was suspended in an ice-cooled $100 \mathrm{~mm}$ potassium phosphate buffer ( $\mathrm{pH} 7.4$ ) (about $4 \mathrm{mg} / \mathrm{ml}$ protein concentration). This suspension was used as the enzyme solution.

Assay of Squalene Synthase Inhibitory Activity Squalene synthase activity was monitored by the formation of $\left[{ }^{3} \mathrm{H}\right]$ squalene from $\left[1-{ }^{3} \mathrm{H}\right]$ farnesyl pyrophosphate. Fifty microliters of assay mixture included $5 \mu \mathrm{M}$ [1${ }^{3} \mathrm{H}$ ]farnesyl pyrophosphate $(25 \mu \mathrm{Ci} / \mathrm{mol}), 1 \mathrm{~mm} \mathrm{NADPH}, 5 \mathrm{~mm} \mathrm{MgCl} 2,6 \mathrm{~mm}$ glutathione, $100 \mathrm{~mm}$ buffer solution of potassium phosphate $(\mathrm{pH} 7.4)$, the test compound dissolved in dimethyl sulfoxide (DMSO) (a final concentration of DMSO was $2 \%$ ) and enzyme solution prepared from rat or HepG2 cells (protein content $0.8 \mu \mathrm{g}$ ). The assay ran $45 \mathrm{~min}$ at $37^{\circ} \mathrm{C}$ and stopped by adding $150 \mu \mathrm{l}$ of $\mathrm{CHCl}_{3}-\mathrm{MeOH}(1: 2)$ containing $0.2 \%$ cold squalene as carrier. Aqueous solution of $3 \mathrm{~N} \mathrm{NaOH}(50 \mu \mathrm{M})$ and $\mathrm{CHCl}_{3}(50 \mu \mathrm{M})$ were added to the mixture. The chloroform layer containing the reaction mixture having squalene as the principal component and $3 \mathrm{ml}$ of toluene-based liquid scintillator were mixed, and its radioactivity was determined by means of a liquid scintillation counter. The squalene synthase inhibitory activity was expressed in terms of the concentration of the test compound inhibiting by 
$50 \%$ the radioactivity taken into the chloroform layer $\left(\mathrm{IC}_{50}\right.$, molar concentration (M)).

Single-Crystal X-Ray Analysis. 7a: Unit cell parameters $[a=11.245$ (1) $\AA, b=11.746$ (1) $\AA, c=9.067$ (1) $\AA, \alpha=107.26(1)^{\circ}, \beta=98.64(1)^{\circ}, \gamma=$ $\left.74.94(1)^{\circ}\right], Z=2$, space group $P 1, R$-factor $=0.080$.

7b: Unit cell parameters $[a=10.854$ (1) $\AA, b=11.083$ (1) $\AA, c=9.807$ (1) $\left.\AA, \alpha=108.20(1)^{\circ}, \beta=96.53(1)^{\circ}, \gamma=94.13(1)^{\circ}\right], Z=2$, space group $P 1, R$ factor $=0.083$

2a: Unit cell parameters $[a=10.018$ (1) $\AA, b=11.304$ (1) $\AA, c=8.508$ (1) $\left.\AA, \alpha=93.87(1)^{\circ}, \beta=98.23(1)^{\circ}, \gamma=91.83(1)^{\circ}\right], Z=2$, space group $P 1, R$ factor $=0.063$

Acknowledgments The authors wish to thank Dr. Kanji Meguro for his encouragement and helpful discussion throughout this study. We also thank Mr. Akira Fujishima and Ms. Keiko Higashikawa for X-ray crystallographic analysis.

\section{References and Notes}

1) Part 3 in the series of studies on 4,1-benzoxazepine derivatives as squalene synthase inhibitors; a) Part 1: Miki T., Kori M., Fujishima A., Mabuchi H., Tozawa R., Nakamura M., Sugiyama Y., Yukimasa H., Bioorg. Med. Chem., 10, 385-400 (2002); b) Part 2: Miki T., Kori M., Mabuchi H., Banno H., Tozawa R., Nakamura M., Itokawa S., Sugiyama Y., Yukimasa H., ibid., 10, 401-414 (2002).

2) Yukimasa H., Kori M., Tozawa R., Sigiyama Y. (Takeda), Eur. Patent, 645377 (1995) [Chem. Abstr., 123, 256777w (1995)].
3) Tamai M., Yokoo C., Murata M., Oguma K., Sota K., Sato E., Kanaoka Y., Chem. Pharm. Bull., 35, 1098-1104 (1987).

4) Reaction of 5a with 4-nitrophenyl ester ${ }^{3)}$ of DL-trans-epoxysuccinic acid monoethyl ester did not proceed.

5) Yamamoto M., Yoshitake M., Kishikawa K., Kohmoto S., Yuki Gosei Kagaku Kyokai Shi., 50, 638-651 (1992).

6) Only one spot was detected by TLC analysis of the mixture of 7a and 7b. Separation of the mixture by column chromatography was unsucessful, even when this mixture was converted to acetate or benzoate.

7) We initially tried to synthesize the epimer [( $3 R S, 5 S R, \alpha R S)$-derivative] of 7a using cesium propionate, which is a reagent for inversion of the configuration of secondary alcohol. Kruizinga W. H., Strijtveen B., Kellogg R. M., J. Org. Chem., 46, 4321-4323 (1981).

8) The mechanism of this elimination is considered to be E1cB.

9) Cohen L. H., Griffioen A. M., Wanders R. J. A., Van Roermund C. W. T., Huysmans C. M. G., Princen H. M. G., Biochem. Biophys. Res. Commun., 138, 335-341 (1986).

10) The active conformation of 5-naphtyl-4,1-benzoxazepine derivative in the crystal of protein-inhibitor complex supports our results. Pandit J., Danley D. E., Schulte G. K., Mazzalupo S., Pauly T. A., Hayward C. M., Hamanaka E. S., Thompson J. F., Harwood H. J., Jr., J. Biol. Chem., 275, 30610-30617 (2000).

11) Davisson V. J., Woodside A. B., Poulter C. D., Methods Enzymol., 110, $130-144(1985)$. 